\title{
Quince años de un pronunciamiento
}

\begin{abstract}
Fl 5 de febrero de 1992, el Consejo Superior - Universitario de la Universidad Centroamericana "José Simeón Cañas" dio a conocer un pronunciamiento en el que daba a conocer sus valoraciones acerca de la firma de los Acuerdos de paz, ocurrida poco más de un mes antes, en el castillo de Chapultepec, México. Bajo el título "El Acuerdo de paz: expectativas y riesgos", la Universidad expresaba cuáles eran sus esperanzas y sus preocupaciones, pero también hacía públicos sus compromisos ante la sociedad salvadoreña a partir de la nueva realidad histórica que se abría para el país.

Los tres lustros transcurridos después de la firma de los Acuerdos hacen necesario volver la mirada a ese documento. Escrito y publicado cuando la tinta de los mencionados Acuerdos estaba fresca. Como es natural, ante un hecho de tal magnitud predominaban reacciones encontradas en la sociedad. El pronunciamiento es un esfuerzo por ir más allá de las reacciones emocionales o ideológicas, para ofrecer una valoración más serena y ponderada sobre los hechos.
\end{abstract}


Visto hoy en día, el mencionado pronunciamiento da la posibilidad de confrontar el proyecto de país proveniente de los Acuerdos de 1992 con la situación actual de El Salvador después de esos Acuerdos.

Un elemento promisorio de los Acuerdos, y sin lugar a dudas, el logro más importante y consolidado de los mismos, fue la desmilitarización de la sociedad. Afirma el pronunciamiento: "La mayor parte del Acuerdo de paz está dedicada [...] a la desmilitarización de la sociedad, que está tratada con sumo cuidado y detalle en el texto acordado". La UCA valoraba, en aquel momento, que ello podía dar pie a una nueva dinámica social y política en la que los grandes problemas del país debían y podían ser enfrentados "políticamente por todas las fuerzas sociales". Los cambios en el ejército, la creación de la Policía Nacional Civil y la incorporación del FMLN a la política partidaria constituían indicios de que esta nueva dinámica era posible.

Sin embargo, la prolijidad con que se trató el tema de la desmilitarización de la sociedad salvadoreña se contrasta con el tratamiento de otros problemas, igualmente acuciantes, sobre todo aquellos vinculados a "la injusta estructura económica". Para las autoridades universitarias, el callar de las armas y el desmontaje del militarismo en sus distintas modalidades, pondría en evidencia la importancia de resolver los problemas económicos estructurales para consolidar socialmente lo que en el orden de las conquistas políticas podía lograrse.

Visto a la distancia de quince años, esta disparidad entre la importancia con que se abordaron la desmilitarización y las libertades políticas y el tratamiento superficial del tema económico es uno de los factores configuradores de los problemas actuales y que condicionan seriamente las proyecciones del país para el futuro. Si bien la sociedad salvadoreña ha tenido importantes avances, cuando no rotundos logros sobre temas como el de la desmilitarización de la sociedad, es notable también lo poco que se ha avanzado en la superación de las estructuras económicas injustas. Los logros políticos alcanzados -incorporación del FMLN al sistema partidario y un considerable avance en libertades políticas, tales como la libertad de expresión y organización - no compensan la persistencia de la injusticia estructural, que hunde sus raíces en el orden económico del país. No es este el país agrario, que, por su misma índole, encendió durante décadas la mecha del descontento social en una población predominantemente campesina, ni tampoco es el país del desarrollismo autoritario, liderado por los militares, especialmente a partir de 1950. Pero sí es el país que niega, en virtud de las políticas neolibe- 
rales impuestas por el consenso de Washington, las posibilidades reales para que la mayoría de su población tenga una vida realmente humana y personalizadora, excluyéndola y forzándola a vivir en una precariedad económica y social escandalosa, estimulando así la emigración hacia el exterior. Incluso las libertades políticas alcanzadas tampoco son suficientes para presumir del país y su "sistema de libertades". En términos de sistema político democrático, éste no ha sido capaz de pasar, como dicen algunos analistas, por la prueba de la alternabilidad en el poder. La mera posibilidad de un cambio en el Ejecutivo hacia la izquierda aún desata las reacciones más viscerales y paranoicas de la derecha económica y política, incluso de la militar.

Por otra parte, los partidos políticos están desprestigiados y cada vez más son vistos con desconfianza por parte de la población, que los percibe más abocados a sacar adelante sus intereses partidarios y orientados hacia el clientelismo, la corrupción y la obtención de ventajas personales. Además, las expresiones de descontento de grupos y organizaciones sociales, y las demandas de solución a sus problemas locales, no son procesadas democráticamente, pues son interpretadas a priori por los funcionarios gubernamentales como una amenaza, no sólo contra el partido en el gobierno, sino contra el sistema capitalista neoliberal. Los sectores oficialistas y los medios de comunicación ligados a los sectores dominantes presentan ideologizadamente a las organizaciones sociales y sus acciones como parte de una estrategia antisistémica, supuestamente diseñada por los "comunistas" para implantar una dictadura a la cubana. Se ha llegado al colmo, incluso, de vincular la delincuencia y la criminalidad de las maras con un supuesto "complot comunista", auspiciado por Chávez y Fidel Castro, pretendiendo enmascarar así las raíces socio-económicas y culturales, y toda la complejidad del problema de la violencia social y de la criminalidad que padece actualmente el país. Los nostálgicos ultraderechistas del pasado militarista vuelven a recordar la necesidad de repetir otro "32" para acabar con la violencia social que ellos interpretan como parte de un "plan subversivo" del comunismo internacional.

Lo anterior se relaciona con una idea que recorre todo el pronunciamiento de la UCA del 5 de febrero de 1992: la necesidad de que los distintos sectores sociales cobren protagonismo y que tengan a su disposición espacios para incidir en las decisiones sobre el rumbo del país. La cita de Ignacio Ellacuría que encabeza el pronunciamiento ("que el pueblo haga oír su voz") hace énfasis en este tema, crucial para poder 
medir la profundidad de las transformaciones originadas por los Acuerdos. Tras constatar que éstos no presentaron una alternativa al modelo económico imperante, para la UCA, el foro económico social era una instancia que podía servir para empujar las transformaciones necesarias, desde la base de la participación de los distintos sectores de la sociedad. Ello requería de un compromiso fuerte con el país por parte de los sectores económicamente dominantes, más que con sus intereses particulares, puesto que abrir la discusión para solucionar los problemas económicos implicaba hacer una "evaluación del modelo actual, considerando sus logros macroeconómicos, pero también las contradicciones sociales que ha generado; asimismo - se decía - el foro debe considerar alternativas técnicas que favorezcan a las mayorías populares, porque la pobreza no puede esperar ya más tiempo".

El foro económico-social concluyó en un fracaso, dada la intransigencia de los de los grupos económicos hegemónicos. Eso ya planteaba un signo preocupante, puesto que con ello dejaban claro que el modelo económico imperante era intocable. Haciendo un supremo esfuerzo y empujados por las condiciones históricas, se podía tocar a la fuerza armada, se podía admitir la libre participación política de la antigua guerrilla, pero no podía tocarse, ni con el pétalo de la rosa de la discusión, ya no digamos con compromisos sustanciales, al modelo económico. Este sigue siendo un dogma inamovible en El Salvador de 2007. Esto se evidenció con la negativa de ARENA de firmar un acuerdo político con el FMLN, con ocasión del quince aniversario de los acuerdos de paz, para ratificar y profundizar la democracia, el cual incluía la necesidad de un pacto fiscal para aumentar los ingresos del Estado con el fin de financiar los proyectos sociales. El resultado de ese grave error político del gobierno arenero fue que no se ratificaran los prestamos por parte de la Asamblea Legislativa, en el pasado marzo.

Un desafío importante que recoge el pronunciamiento es el mantener viva la memoria histórica. El tema de la memoria histórica ha sido recogido por distintos sectores de la sociedad. Pero habría que cuestionarse: ¿Memoria histórica desde quiénes y para qué? Esto parece bastante obvio: Memoria histórica desde las víctimas y para ayudarnos a superar las causas que generaron esas víctimas. Sin embargo, el tema de la memoria histórica corre el riesgo de desvirtuarse, si no se tiene claridad sobre el punto anterior. Hay quienes, desde la posición de los victimarios de la guerra, hablan también de memoria histórica.

Finalmente, el pronunciamiento del Consejo Superior Universitario ex- 
presa los términos del compromiso que la UCA estaba dispuesta a asumir en la nueva realidad que se gestaba con los Acuerdos de paz: poner la razón universitaria al servicio de la razón popular, para contribuir al proceso de liberación de las mayorías populares, desde instrumentos y perspectivas específicamente universitarias; la promoción de los bienes sociales y de las virtudes del pueblo salvadoreño; ayudar a mantener viva la memoria de las víctimas y mantener viva la esperanza para que el desánimo no forzara a abandonar los compromisos adquiridos con los Acuerdos.

A quince años de aquel pronunciamiento el contexto sociopolítico y económico han cambiado, a pesar de que las condiciones estructurales que producen inequidades y exclusión social para las mayorías sociales se mantienen. La UCA, a través de diferentes medios, se ha venido pronunciado al respecto y sigue reconociendo que son palpables muchos temas inconclusos de los Acuerdos de paz.

En aquel entonces, la Universidad expresó claramente las reservas sobre aquellos temas que no fueron abordados con profundidad. Sin embargo, en el documento no podía preverse la magnitud del agravamiento de los problemas socio-económicos como producto de la falta de solución de los problemas que planteaban los Acuerdos, desde su redacción final, pasando por su seguimiento y por los temas que siguen pendientes de solución. En ese sentido, la Universidad no puede menos que seguir comprometida con aquel pronunciamiento a partir de las exigencias del presente.

\section{Anexo}

Pronunciamiento del Consejo Superior Universitario de la Universidad Centroamericana "José Simeón Cañas"

\section{El Acuerdo de paz: expectativas y riesgos}

Publicado en ECA, Números 519-520, enero-febrero de 1992.

...que el pueblo haga oír su voz, que el pueblo reflexione desde el punto de vista de la Iglesia, en sus comunidades de base, desde el punto de vista más social, en sus cantones, en sus comunidades; que reflexionen sobre la situación del país, que exijan ser bien informados, que hagan sentir a ambas partes en conflicto e incluso al mundo internacional, que hagan sentir cuál es su sensación, cuán cansados están de la guerra, cuán cansados están de la violencia, cuán cansados están del terrorismo, cómo se necesita cuanto antes un desarrollo económico profundo del país, cómo se necesita que se resuelva su problema de injusticia, es decir, yo lo resumiría en que el pueblo salvadoreño haga sentir su voz.

IgNACIO ElLACURÍA 
La Universidad Centroamericana "José Simeón Cañas" saluda la llegada del cese del fuego y se une al júbilo nacional que, desde el 31 de diciembre de 1991, viene celebrando cada paso que nos aleja firmemente de la guerra y nos lleva hacia una nueva posibilidad para convivir fraterna y solidariamente, y para crear condiciones para transformar esta sociedad en otra más justa.

Con orgullo nos sentimos parte de este gran proceso, en el cual hemos estado presentes desde el comienzo, clamando que no había salida militar, que era necesario dialogar y negociar. Desde 1981, Ignacio Ellacuría no se cansó de repetir que no había otra salida que la político diplomática y tuvo razón, tal como al final lo ha demostrado la historia.

En estos momentos de regocijo nacional, recordamos con cariño a nuestros mártires, así como también a todos los profesores y estudiantes de la UCA que cayeron en esta larga guerra. Participamos del sentir popular que admira y se alegra, pero que también recuerda a quienes no han podido llegar a este prometedor amanecer.

\section{Las expectativas}

El Acuerdo de paz ofrece un buen diagnóstico de la situación política y social predominante en El Salvador, así como también pretende dar una respuesta a sus problemas más acuciantes. En la misma medida en que estas respuestas se vayan concretizando, la realidad nacional se irá transformando y estaremos así en vía hacia una nueva nación.

La mayor parte del Acuerdo de paz está dedicado a uno de los elementos fundamentales del diagnóstico, a la desmilitarización de la sociedad, que está tratada con sumo cuidado y detalle en el texto acordado. Por lo tanto, de la aplicación adecuada de esas medidas podemos esperar la transformación de la Fuerza Armada, la cual ya no gozará de un poder absoluto, por encima de la sociedad civil y el derecho, sino que predominará lo civil sobre lo militar. Juntamente con ello, se impondrá un nuevo concepto de seguridad pública, expresado en la supresión de los cuerpos de seguridad, de todos los cuerpos paramilitares existentes y de la Dirección Nacional de Inteligencia, en la creación de la Policía Nacional Civil, caracterizada por su respeto de los derechos humanos y su pluralismo político. Cuando todo esto se haya llevado a cabo, los militares habrán desaparecido de la vida y del debate público.

Estos dos elementos fundamentales del Acuerdo, la transformación de la Fuerza Armada y la creación de la Policía Nacional Civil, sobre los cuales se apoya la nueva fase que ahora comenzamos, están precedidos 
por otros dos acuerdos, el de derechos humanos, que garantiza el fin de las ejecuciones sumarias individuales y colectivas, de las desapariciones forzadas, de las capturas ilegales y de las torturas, y el de las reformas constitucionales, que modifican los sistemas judicial y electoral.

Esperamos, por tanto, que la militarización actual vaya dejando paso a la democratización, es decir, vaya abriendo espacios para la participación efectiva de todas las fuerzas políticas y sociales, respetando las ideas, las ideologías y los credos. Para ello, tendremos que aprender a discutir, abandonando los dogmatismos y sectarismos, y a respetar a los contrarios. Prácticas a los cuales no estamos acostumbrados, pero sin ellas no será posible alcanzar los consensos necesarios para consolidar la democratización. Así, pues, esperamos que la conquista de la democracia se traduzca en una intensa actividad política más cualificada, donde, al final, predominen la racionalidad y el bien común.

El final de la guerra implica la desaparición del militarismo, el factor principal que distorsionaba el quehacer político. En estas nuevas circunstancias, la presencia política del FMLN debe contribuir a transformar el escenario y la lucha políticos. Tiene capacidad para hacerlo, pues cuenta con cuadros decididos a seguir trabajando por la justicia social dentro del contexto democrático. Es previsible, por tanto, que el campo donde se diluciden las grandes decisiones políticas se traslade a la lucha por la sobrevivencia de las mayorías populares en los barrios y cantones, y no tanto a través de las plataformas políticas tradicionales. De esta manera, las mayorías populares, a las cuales siempre se tiende a marginar, ahora tienen delante de sí un reto, para comenzar a participar en la dirección de los destinos de la nación. Esa participación obligará a los partidos políticos a enfrentarse cara a cara con las demandas populares.

La retirada del ejército a sus cuarteles posibilitará la apertura a esta nueva experiencia política. Los graves problemas nacionales deberán ser dirimidos políticamente por todas las fuerzas sociales. El gobierno mismo también tendrá que defender sus programas con instrumentos políticos, puesto que, una vez desaparecida la excusa militar y el apoyo político e ideológico de la Fuerza Armada, habrá perdido su instrumento de dominación más poderoso.

En esta nueva experiencia de vida política no deben malentenderse ni manipularse la paz y la reconciliación. Tampoco se debe recurrir a los pacifismos a ultranza para acallar la participación popular y la protesta social. Las posturas oficiales deben ser discutidas públicamente, tratando de encontrar siempre el bienestar de las mayorías puesto que aquí reside el fundamento de la paz con justicia social. 
Así, pues, el Acuerdo de paz inicia grandes novedades políticas; tantas que algunas hablan del nacimiento de un nuevo país; otros, más escépticos, todavía dudan de su viabilidad después de tantos engaños. Sin embargo, el Acuerdo de paz cuenta con las suficientes garantías como para ser cumplido cabalmente.

La primera garantía es que la oposición tiene capacidad efectiva par supervisar al gobierno por medio de COPAZ. De hecho, COPAZ ya está actuando como supervisor de la actuación gubernamental y del FMLN. Este control de COPAZ sobre el gobierno anuncia el papel influyente y no decorativo que deberá tener la oposición política en el futuro democrático del país. COPAZ ha comenzado a romper la confrontación "derecha e izquierda" y ha puesto las bases para una nueva relación entre el poder y la oposición.

La segunda garantía proviene de la comunidad internacional, que no permitirá sorpresas contrarias al Acuerdo de paz. El compromiso de Estados Unidos con el Acuerdo ha sido claro y contundente. Washington ya ha abandonado la obsesión ideológica y militar, y la falta de sentido común del gobierno de Reagan. Los enemigos de antes se han convertido en interlocutores políticos, con quienes se puede dialogar sobre el futuro del país; mientras que los amigos de la guerra sucia de ayer se han convertido en los nuevos terroristas de la época de paz.

La presencia militar de las Naciones Unidas es otra garantía para el cumplimiento del cese del enfrentamiento armado y la integración del FMLN a la vida política.

Finalmente, pero no en último lugar, está la garantía del mismo pueblo organizado, que vigila el cumplimiento cabal de lo acordado.

Por todo ello, esperamos que el terror introyectado en la conciencia nacional vaya cediendo ante el avance y el respeto de la libertad de opinión, de tal manera que las mayorías populares puedan decir directa y claramente su propia palabra. La fuerza de esta palabra se traducirá en votos capaces de elegir y aun de determinar programas de gobierno. En efecto las campañas electorales ya no serán meramente propagandísticas, sino espacios donde participarán libre y abiertamente las diversas fuerzas políticas y corrientes ideológicas distintas, generando no sólo apertura política, sino también la posibilidad para optar por el partido que se adecue a las aspiraciones de cada quien; ya no se elegirá tanto un determinado candidato, como un programa político concreto. Entonces, los salvadoreños podremos elegir consciente y libremente lo que en realidad queremos. 


\section{Los riesgos}

Los riesgos y dificultades de la paz no radican tanto en la posibilidad de incumplimiento del Acuerdo de paz, sino en lo poco que se negoció sobre el otro gran problema de nuestra realidad nacional, la injusta estructura económica. Junto con la militarización de la sociedad, éste es el tema más vital para el futuro de El Salvador. Mientras hubo guerra, lo militar, además de ser causa de la misma guerra y del militarismo, fue lo más visible y urgente; pero ahora, al comenzar a vivir sin enfrentamiento armado, lo económico irá cobrando la relevancia fundamental que tiene para la convivencia pacífica.

En la mesa de negociación no se llegó a presentar una alternativa al modelo económico actual. Sólo se concretaron algunos puntos limitados sobre la problemática agraria y un mecanismo para concertar un diálogo económico entre los representantes del gobierno, la empresa privada y las clases trabajadoras. Siendo el problema económico el tema fundamental para la pacificación del país, en el foro de concertación económica debe iniciarse la evaluación del modelo actual, considerando sus logros macroeconómicos, pero también las contradicciones sociales que ha generado; asimismo, el foro debe considerar alternativas técnicas que favorezcan a las mayorías populares, porque la pobreza no puede esperar ya más tiempo.

No puede haber concertación económico social sin apertura para cuestionar y reformular el modelo actual. Relegar esta decisión a las próximas elecciones presidenciales es arriesgarse a que todo el modelo estalle antes de esa fecha. El gran reto y la incógnita todavía sin respuesta adecuada es cómo aliviar el escandaloso nivel de pobreza actual con un programa de ajuste estructural.

Las organizaciones populares y sindicales deben dar una dura batalla en el foro, para tratar de conseguir las primeras reformas de la injusta estructura socio-económica actual. Para tener éxito en esta difícil empresa será necesario que profundicen sus estructuras organizativas alrededor de una plataforma consensuada, que recoja las aspiraciones e intereses más sentidos por las mayorías populares. Esta oportunidad, aunque limitada, debe ser aprovechada al máximo por el movimiento popular organizado.

El tema de la reconstrucción está tratado genérica y vagamente en el Acuerdo de paz, lo cual quiere decir que el gobierno actual está en capacidad para imponer su propio plan, sin ninguna garantía de que éste sea 
lo mejor para el bien de la nación. Esto significa también que el gobierno buscará controlar de modo exclusivo la ayuda económica internacional. Sólo la presión de los donantes y la de los sectores populares organizados podrá hacer que el gobierno abra sus horizontes y busque una concertación amplia para formular y ejecutar un plan de reconstrucción con el cual se pudieran comprometer todas las fuerzas sociales del país. Un consenso de envergadura nacional garantizaría mejor la inversión adecuada de fondos provenientes del compromiso de la comunidad internacional con la paz.

Existe también el peligro de reducir la construcción del nuevo país a sus aspectos materiales, olvidando que es necesario establecer sólidamente nuevos fundamentos éticos. El primero de ellos es la verdad debida al país. Ya han aparecido los voceros de las falsas reconciliaciones, invitando a olvidar el pasado de violaciones masivas y sistemáticas de los derechos humanos de decenas de miles de salvadoreños. A propósito de la ley de amnistía, propusieron una amnistía general, entendida como perdón y olvido, es decir, una amnistía que beneficiara directamente a los militares responsables de esas violaciones. Han tenido la osadía de pedir al pueblo salvadoreño que se olvide de lo mejor que tiene, de sus muertos y de sus mártires. En este sentido, existe el peligro real de enterrar el pasado horrendo de la guerra, ocultando la verdad, precisamente, cuando más necesitamos saberla, para reconciliarnos con nosotros mismos y como nación. No se logra la reconciliación y la paz pregonando la impunidad, porque ambas son fruto de la verdad y de la justicia.

\section{Mantener la memoria}

La grandeza y la generosidad hasta el sacrificio total que caracterizan esta larga lucha de doce años, nos llevan a recordar con cariño entrañable los momentos mejores y más difíciles por abrir espacio al derecho y a la justicia.

Los ojos se enturbian y la memoria se vuelve dolorosa cuando también recordamos a los familiares, a los amigos y a los compañeros que cayeron a lo largo de la guerra, en el enfrentamiento, en la acción militar, en las cárceles clandestinas, en manos de los escuadrones de la muerte, en el fuego cruzado, en la tortura, en el asesinato político... Son tantos y tan queridos.

No debemos olvidar cómo llegamos a tan horrendos crímenes y a tanta irracionalidad. La raíz de la violencia está en la pobreza estructural, que durante décadas se ha venido profundizando y consolidando. Cada 
vez son más los salvadoreños pobres. Y no olvidemos que las primeras protestas para cambiar la dinámica de la distribución de la riqueza nacional fueron acalladas, una tras otra, por los cuerpos de seguridad. Cuando las protestas se organizaron, las violaciones de los derechos humanos fueron imponiéndose, hasta convertirse en algo rutinario. Cuando se intentó la vía electoral para, desde el poder del Estado legítimamente conquistado, reformar la sociedad, sacaron el ejército a la calle y lo lanzaron contra las organizaciones que exigían pan y trabajo digno. Cuando la protesta organizada se armó, se desató la guerra, que ahora, al fin, damos por concluida.

No olvidemos nuestras experiencias personales y colectivas en esta oscura guerra, tampoco olvidemos a nuestros queridos mártires, ni de donde provino tanto mal para tantos salvadoreños. De esta memoria histórica debe salir un grito profundo de "nunca más". El Acuerdo de paz ha puesto en nuestras manos la posibilidad para enderezar pronto esta enorme tarea, pero hay que llevarla a cabo considerando siempre lo mejor para los intereses populares. Que esta memoria que ahora recuerda, siempre tenga presente a sus muertos y mártires.

\section{Renovamos nuestro compromiso universitario}

Ante estas expectativas y riesgos, la Universidad Centroamericana "José Simeón Cañas" renueva su compromiso para orientar siempre desde la verdad y desde su saber universitario. Seguiremos poniendo nuestra razón universitaria al servicio de la razón popular, para descubrir su razón y justeza profunda, contribuyendo así al proceso de liberación de las mayorías populares. Nuestro compromiso universitario seguirá dedicado a cultivar la realidad nacional y a desenmascarar las falsedades, si se dieran, de esta nueva fase de nuestra historia. Estaremos alertas para no permitir que los principios éticos sean sacrificados en aras de un pragmatismo fácil.

Renovamos nuestro compromiso con la promoción de los bienes sociales (la democracia, el respeto de los derechos humanos, la promoción del bien común, la salud y la educación para todos, y la cultura) y las virtudes del pueblo salvadoreña (la fe profunda y comprometida con los pobres, la solidaridad, la fraternidad, la dedicación al trabajo, la generosidad), en una palabra, con todo aquello que nos ha mantenido firmes durante esta larga noche que termina.

También nos comprometemos a mantener la memoria de la guerra que finaliza, sobre todo, a no olvidar a los muertos ni a los mártires, no 
por revanchismo ni por masoquismo, sino porque ellos constituyen lo mejor de nuestro pueblo.

Finalmente, nos comprometemos a animar y a mantener la esperanza para que cuando venga el cansancio de la larga marcha hacia la paz y la justicia, no abandonemos el compromiso histórico contraído en este Acuerdo.

El fin del enfrentamiento armado y el comienzo de la paz necesitan monumentos, pero éstos carecerán de sentido si no responden a nuevas realidades sociales y culturales. Si no van acompañados de una nueva realidad social, serán monumentos inútiles, destinados al olvido. El mejor monumento, y el más difícil, consiste en liberar a nuestra sociedad de la pobreza y de la injusticia.

San Salvador, 5 de febrero de 1992. 